\title{
"ANALISIS PEMBENTUKAN PORTOFOLIO OPTIMAL DENGAN MENGGUNAKAN SINGLE INDEX MODEL PADA EMITEN YANG TERMASUK KE DALAM INDEKS LQ-45 PERIODE 2011- 2016"
}

\author{
Hana Tamara Putri, Santi Dwi Lestari \\ Program Studi Manajemen, Fakultas Ekonomi, Universitas Batang Hari
}

\begin{abstract}
Research portfolio optimal aims to understand return and risks portfolio, and know how much teh proportion of funds invested. The period used in this reseach was februari 2011-januari 2016. Population to research there are stock companies joined in LQ-45 index. The sample of the research are 21 sample. The data collected is secondary data. Tekhnik data analysis used in research this is the kind of index singular to know shares from portrfolio optimal. Shares who was a candidate portfolio optimal are stocks having the value ERB greater than or equal to cut off-rate. Portfolio optimal formed by the shares having value ERB more of the value of cut of rate that is 0.0031 . Based on the research done showed 10 stock who was a candidat portfolio optimal from 21 sample. The propotion of funds drom 10 company is: UNVR of $31.18 \%$, ICBP of 20.40\%, GGRM of 5.84\%, BBCA of $14.83 \%$, CPIN of 5.05\%, JSMR of $10.08 \%$, LPKR of $4.82 \%$, BBRI of $6.01 \%$, INTP of $1.16 \%$, dan BMRI of $0.63 \%$. Expected return portfolio receive is $1.73 \%$ monthly with the risk $0.2 \%$. the conclusion that obtained was that investors rational to invest the funds to into the optimal portfolio of 10 shares formed.
\end{abstract}

Keyword : investation, optimal stock

\section{PENDAHULUAN}

Investasi adalah "komitmen atas sejumlah dana atau sumber daya lainnya yang dilakukan pada saat ini dengan tujuan memperoleh keuntungan di masa datang" (Tandelilin, 2007). Investasi merupakan cara lain dalam persiapan keuangan di masa depan. Sebab investasi mampu memberikan tingkat pengembalian yang lebih tinggi dibandingkan dengan jumlah yang diinvestasikan.

Banyaknya jumlah perusahaan yang listing di BEI membuat para investor bingung untuk menentukan saham mana yang aman, terbaik dan layak untuk dibeli. Maka dari itu BEI berusaha membantu para investor dengan membentuk suatu indeks yang dikenal dengan indeks liquid 45 (LQ-45). Indeks ini terdiri dari saham-saham yang memiliki kapitalisasi pasar yang besar dan tingkat liquiditas yang tinggi.

Untuk menghitung saham optimal kita menggunakan data-data saham pada indeks LQ-45 pada periode 2011-2016, yaitu data harga penutupan (Closing Price) akhir bulan. 
Tabel 1.2

Tabel Return IHSG, LQ-45, dan BI Rate Periode

Februari 2011 - Januari 2016

\begin{tabular}{|c|c|c|c|c|c|c|c|c|c|c|c|c|c|c|c|}
\hline \multirow{2}{*}{ Bulan } & \multicolumn{3}{|c|}{ Return } & \multirow{2}{*}{ Bulan } & \multicolumn{3}{|c|}{ Return } & \multirow{2}{*}{ Bulan } & \multicolumn{3}{|c|}{ Return } & \multirow{2}{*}{ Bulan } & \multicolumn{3}{|c|}{ Return } \\
\hline & IHSG & LQ-45 & BI Rate & & IHSG & $\mathrm{LQ}-45$ & BI Rate & & IHSG & LQ-45 & BI Rate & & IHSG & LQ-45 & BI Rate \\
\hline Feb-11 & 0.0179 & 0.0270 & 0.0385 & Sep-12 & 0.0498 & 0.0521 & 0.0000 & Apr-14 & 0.0151 & 0.0193 & 0.0000 & Nov-15 & -0.0020 & -0.0056 & 0.0000 \\
\hline Mar-11 & 0.0600 & 0.0733 & 0.0000 & 0kt-12 & 0.0206 & 0.0264 & 0.0000 & Mei-14 & 0.0111 & 0.0118 & 0.0000 & Des-15 & 0.0330 & 0.0484 & 0.0000 \\
\hline Apr-11 & 0.0383 & 0.0327 & 0.0000 & Nov-12 & -0.0170 & -0.0324 & 0.0000 & Jun-14 & -0.0031 & -0.0023 & 0.0000 & Jan-16 & 0.0048 & 0.0101 & -0.0333 \\
\hline Mei-11 & 0.0045 & 0.0024 & 0.0000 & Des-12 & 0.0095 & 0.0113 & 0.0000 & Jul-14 & 0.0431 & 0.0555 & 0.0000 & Jumlah & 0.3533 & 0.3556 & 0.1245 \\
\hline Jun-11 & 0.0134 & 0.0123 & 0.0000 & Jan-13 & 0.0317 & 0.0357 & 0.0000 & Agt-14 & 0.0094 & 0.0010 & 0.0000 & Rata-rata & 0.0059 & 0.0059 & 0.0021 \\
\hline Jul-11 & 0.0623 & 0.0567 & 0.0000 & Feb-13 & 0.0768 & 0.0834 & 0.0000 & Sep-14 & 0.0001 & 0.0045 & 0.0000 & Risik0 & 0.0407 & 0.0461 & 0.0228 \\
\hline Agt-11 & -0.0700 & -0.0734 & 0.0000 & Mar-13 & 0.0303 & 0.0147 & 0.0000 & 0kt-14 & -0.0093 & -0.0058 & 0.0000 & & & & \\
\hline Sep-11 & -0.0762 & -0.0793 & 0.0000 & Apr-13 & 0.0188 & 0.0242 & 0.0000 & Nov-14 & 0.0119 & 0.0211 & 0.0333 & & & & \\
\hline 0kt-11 & 0.0681 & 0.0850 & $\begin{array}{c}-0.0370 \\
\end{array}$ & Mei-13 & 0.0069 & -0.0206 & 0.0000 & Des-14 & 0.0150 & 0.0138 & 0.0000 & & & & \\
\hline Nov-11 & -0.0200 & -0.0284 & $\begin{array}{c}-0.0769 \\
\end{array}$ & Jun-13 & -0.0493 & -0.0423 & 0.0435 & Jan-15 & 0.0119 & 0.0150 & 0.0000 & & & & \\
\hline Des-11 & 0.0288 & 0.0261 & 0.0000 & Jul-13 & -0.0433 & $\begin{array}{r}-0.0399 \\
\end{array}$ & 0.0833 & Feb-15 & 0.0304 & 0.0382 & -0.0323 & & & & \\
\hline Jan-12 & 0.0313 & 0.0277 & 0.0000 & Agt-13 & $\begin{array}{c}-0.0901 \\
\end{array}$ & $\begin{array}{r}-0.0918 \\
\end{array}$ & 0.0769 & Mar-15 & 0.0125 & 0.0159 & 0.0000 & & & & \\
\hline Feb-12 & 0.0110 & 0.0009 & 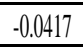 & Sep-13 & 0.0289 & 0.0169 & $\begin{array}{l}0.0357 \\
\end{array}$ & Apr-15 & -0.0783 & -0.0962 & 0.0000 & & & & \\
\hline Mar-12 & 0.0342 & 0.0286 & 0.0000 & $0 \mathrm{kt}-13$ & 0.0451 & 0.0588 & 0.0000 & Mei-15 & 0.0255 & 0.0399 & 0.0000 & & & & \\
\hline Apr-12 & 0.0144 & -0.0016 & 0.0000 & Nov-13 & -0.0564 & -0.0661 & 0.0345 & Jun-15 & -0.0586 & $\begin{array}{c}-0.0719 \\
\end{array}$ & 0.0000 & & & & \\
\hline Mei-12 & -0.0832 & -0.0923 & 0.0000 & Des-13 & 0.0042 & 0.0089 & 0.0000 & Jul-15 & -0.0220 & -0.0310 & 0.0000 & & & & \\
\hline Jun-12 & 0.0320 & 0.0451 & 0.0000 & Jan-14 & 0.0338 & 0.0431 & 0.0000 & Agt-15 & -0.0610 & -0.0520 & 0.0000 & & & & \\
\hline Jul-12 & 0.0472 & 0.0563 & 0.0000 & Feb-14 & 0.0456 & 0.0471 & 0.0000 & Sep-15 & -0.0634 & -0.0854 & 0.0000 & & & & \\
\hline Agt-12 & -0.0198 & -0.0242 & 0.0000 & Mar-14 & 0.0320 & 0.0294 & 0.0000 & $0 \mathrm{kt}-15$ & 0.0548 & 0.0777 & 0.0000 & & & & \\
\hline
\end{tabular}

Sumber : $\underline{w w w . f i n a n c e . y a h o o . c o m}$ 2011-2016 yang telah diolah

\section{Grafik 1.1}

\section{Grafik LQ-45 dan BI Rate}

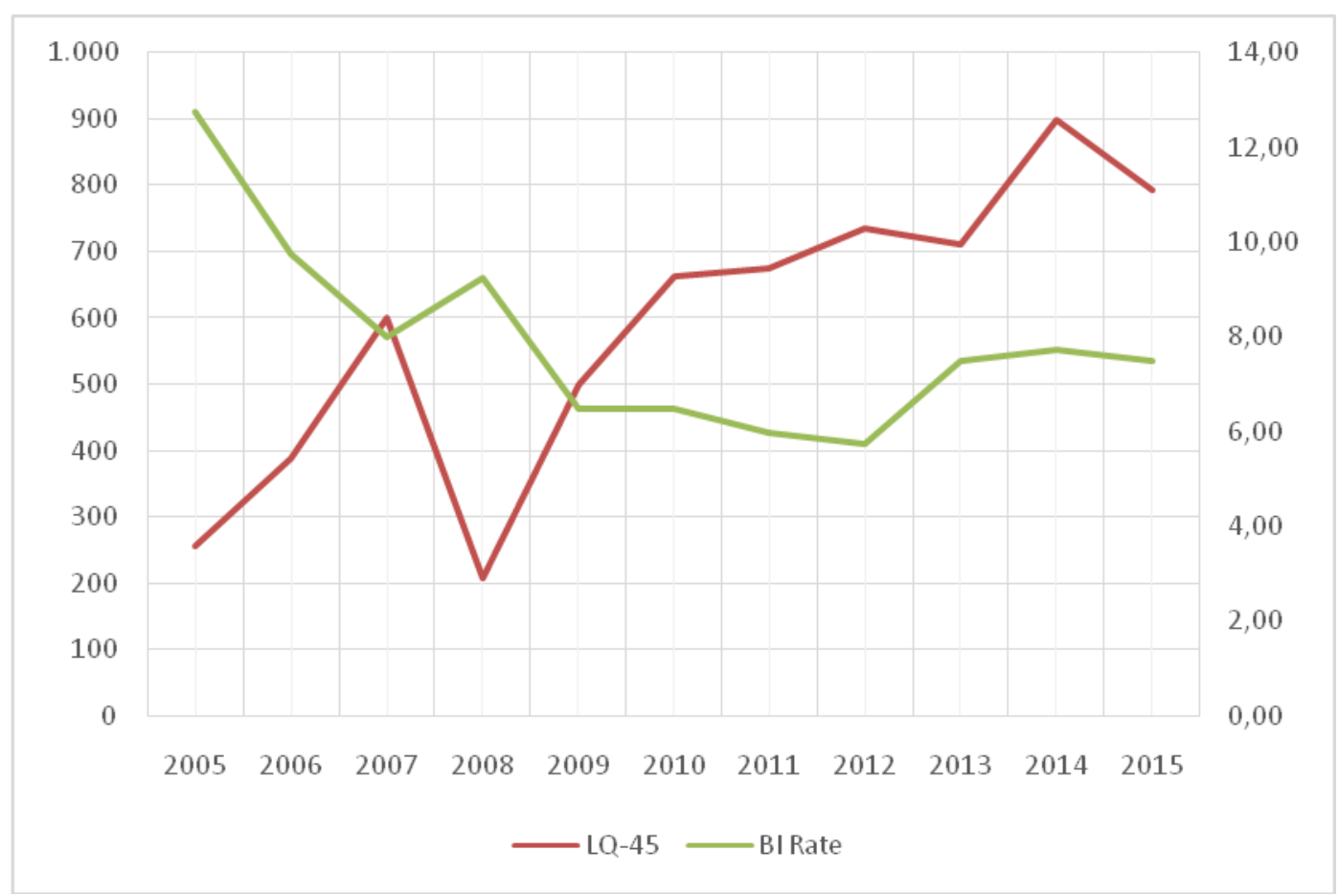

Sumber: www.Investing.com dan www.bi.go.id 2011-2015 
Berdasarkan latar belakang diatas, maka penulis memilih judul "Analisis pembentukan portofolio optimal dengan menggunakan single index model pada emiten yang termasuk ke dalam indeks LQ-45 periode 2011- 2016".

Berdasarkan latar belakang masalah diatas maka rumusan masalah pada penelitian ini adalah sebagai berikut: 1) Berapakah expected return dan risiko dari portofolio optimal yang terbentuk? 2) Apakah saham-saham yang termasuk indeks LQ-45 periode Februari 2011 - Januari 2016 termasuk ke dalam portofolio optimal? 3) Berapakah besarnya proporsi dana dari masing-masing saham dalam pembentukan portofolio optimal?

Tujuan dari penelitian ini adalah: 1) Untuk mengetahui expected return dan risiko dari portofolio optimal yang terbentuk. 2) Untuk mengetahui saham-saham yang termasuk indeks LQ-45 periode Februari 2011 - Januari 2016 termasuk ke dalam portofolio optimal. 3) Untuk mengetahui seberapa besarnya proporsi dana dari masing-masing saham dalam pembentukan portofolio optimal.

\section{TINJAUAN PUSTAKA}

\section{Landasan Teori}

\section{Harga Saham}

Indeks Harga Saham (IHS) merupakan ringkasan dari pengaruh simultan dan kompleks dari berbagai macam variabel yang berpengaruh, terutama tentang kejadian-kejadian ekonomi.

\section{Indeks LQ-45}

Indeks LQ-45 menurut Bursa Efek Indonesia adalah nilai kapitalisasi pasar dari 45 saham yang memiliki nilai kapitalisasi yang besar dan memiliki likuiditas yang tinggi.

\section{Portofolio}

Dalam pembentukan portofolio, investor selalu ingin memaksimalkan return yang diharapkan dengan tingkat risiko tertentu yang bersedia ditanggungnya atau mencari portofolio yang menawarkan risiko terendah dengan tingkat return tertentu.

\section{METODOLOGI PENELITIAN}

\section{Metode Penelitian yang digunakan}

Jenis penelitian ini termasuk ke dalam penelitian deskriptif kuantitatif.

\section{Jenis dan sumber data}

Jenis data yang digunakan dalam penelitian ini adalah data sekunder yaitu data-data closing price saham indeks LQ-45 dan Indeks Harga Saham Gabungan (IHSG) perbulan selama periode Februari 2011- Januari 2016 dan tingkat suku bunga bank (SBI). Sumber data berasal dari dari www.idx.co.id, dan www.finance.yahoo.com.

\section{Populasi}

Populasi dalam penelitian ini adalah perusahaan yang tergolong dalam indeks LQ-45 periode Februari 2011- Januari 2016.

\section{Sampel}

Sampel pada penelitian ini sebanyak 21 perusahaan dimana perusahaanperusahaan tersebut telah memenuhi kriteria untuk penelitian ini yaitu: Emiten yang listing di Bursa Efek Indonesia selama periode Februari 2011- Januari 2016, Emiten yang termasuk LQ-45 selama periode penelitian, Emiten yang selalu masuk dalam indeks LQ-45 periode Agustus - Januari selama periode 
penelitian, Emiten yang tidak mengalami stock split atau stock averse selama periode penelitian.

Berikut adalah daftar nama-nama perusahaan yang menjadi sampel dalam penelitian ini adalah : Astra Agro Lestari Tbk (AALI), Adaro Energy Tbk (ADRO), Bank Central Asia Tbk (BBCA), Bank Negara Indonesia (Persero) Tbk (BBNI), Bank Rakyat Indonesia (Persero) Tbk (BBRI), Bank Mandiri (Persero) Tbk (BMRI), Bank Mandiri (Persero) Tbk (CPIN), XL Axiata Tbk (EXCL), Gudang GaramTbk (GGRM), Indofood Tbk (ICBP), International Nickel Tbk (INCO), Indofood Sukses Makmur (INDF), Indocement Tbk (INTP), Indo Tambang (ITMG), Jasa Marga Tbk (JSMR), Lippo Karawaci Tbk (LPKR), Perusahaan Gas Negara Tbk (PGAS), Tambang batubara (PTBA), Semen Gresik (SMGR), United Tractor (UNTD), Unilever Tbk (UNVR)

\section{HASIL PENELITIAN}

\section{Hasil perhitungan Expected Return, Variance, Standar Deviasi dan Kovarian Saham}

Berdasarkan perhirtungan expected return ada 6 perusahaan yang memiliki return negatif, yaitu saham ADRO, EXCL, INCO, ITMG, PGAS, dan PTBA.

\section{Hasil perhitungan Return Market}

Berdasarkan tabel diatas, data IHSG yang digunakan untuk mewakili data pasar mempunya expected return market sebesar 0,0059 atau sebesar $0,59 \%$ perbulan dan standar deviasi 0.0404 atau sebesar 4,04\%. Sedangkan risiko pasar yang ditanggung sebesar 0,0016 atau sebesar 0,16\%. Expected return market yang bernilai positif menunjukkan bahwa investasi di pasar modal memberikan return bagi investor.

\section{Hasil perhitungan Return Bebas Risiko}

Berdasarkan tabel diatas apabila seseorang berinvestasi pada SBI maka keuntungan yang diharapkan adalah sebesar $0,60 \%$ perbulan pada Januari 2016 dengan risiko $0 \%$.

\section{Hasil perhitungan Alpha, Beta, Variance Error Residual dan Excess Return to Beta}

Berdasarkan perhitungan yang memiliki beta tertinggi yaitu perusahaan Charoen Pokphan Indonesia Tbk (CPIN) sebesar 1,9104. Hal ini dapat diartikan apabila ada return market meningkat satu satuan maka akan ada peningkatan return saham CPIN Tbk sebesar 1.1904 satuan.Untuk memilih kandidat portofolio dari LQ-45 periode Februari 2011- Januari 2016 maka diperlukan perhitungan Excess Return to Beta (ERB). ERB merupakan kelebihan pengembalian atas return bebas risiko dan aset lain. Berdasarkan perhitungan 15 saham perusahaan, saham yang memiliki ERB tertinggi adalah UNVR Tbk yaitu sebesar 0,1153, sedangkan yang memiliki ERB terendah adalah AALI Tbk yaitu sebesar -0,0118.

\section{Menghitung Cut-Off Rate (Ci)}

Nilai $\mathrm{Ci}$ merupakan hasil bagi variance market dan return premium terhadap variance error saham dengan variance market pada sensitivitas saham individual terhadap variance error residual saham.

\section{Menentukan Unique Cut-Off Point ( $\left.\mathrm{C}^{*}\right)$}

Nilai unique cut-off point $\left(\mathrm{C}^{*}\right)$ adalah nilai $\mathrm{Ci}$ maksimum dari sederetan nilai $\mathrm{Ci}$ saham. Nilai $\mathrm{C}^{*}$ digunakan untuk menentukan titik pembatas saham 
mana saja yang masuk sebagai kandidat portofolio optimal. Portofolio terbentuk dari saham-saham yang mempunyai nilai ERB lebih besar atau sama dengan Cut-off rate. Hasil perhitungan nilai $\mathrm{C}^{*}$ pada penelitian ini adalah sebesar 0,0031 dan nilai ERB 0,0155 yaitu perusahaan (ICBP) Indofood CBP Sukses Makmur Tbk

Pada model indeks tunggal langkah-langkah yang dilakukan yaitu mengurutkan saham-saham yang mempunyai nilai ERB tertinggi ke terendah. Pada penelitian ini terdapat 10 saham yang menjadi kandidat portofolio optimal yang diurutkan dari nilai ERB tertinggi sampai terendah.

Dari perhitungan ada 13 saham yang termasuk kandidat dalam pembentukan portofolio optimal.

\section{Hasil Perhitungan Skala Tertimbang dan Proporsi Dana}

Setelah mengetahui ada 10 saham yang terpilih masuk ke dalam Pembentukan portofolio optimal, maka dapat dihitung besarnya proporsi dana (Wi) yang layak diinvestasikan pada saham-saham yang terpilih tersebut.

Komposisi proporsi dana (Wi) untuk membentuk portofolio yang optimal UNVR sebesar 0,3118 atau sebesar 31,18\%. ICBP sebesar 0,2040 atau sebesar 20,40\%. GGRM seebesar 0,0584 atau sebesar 5,84\%. BBCA sebesar 0,1483 atau sebesar 14,83\%. CPIN sebesar 0,0505 atau sebesar 5,05\%. JSMR sebesar 0,1008 atau sebesar $10,08 \%$. LPKR sebesar 0,0482 atau sebesar 4,82\%. BBRI sebesar 0,0601 atau sebesar $6,01 \%$. INTP sebesar 0,0116 atau sebesar $1,16 \%$. BMRI sebesar 0,0063 atau sebesar 0,63\%.

\section{Hasil Perhitungan Return Portofolio}

Setelah mengetahui saham-saham yang terpilih dalam pembentukan portofolio beserta proporsi dananya, maka dapat dihitung expected return portofolio. Untuk menghitung return portofolio, terlebih dahulu menghitung alpha dan beta dari portofolio. Alpha portofolio diperoleh dari rata-rata tertimbang dari alpha tiap saham individual sedangkan beta portofolio diperoleh dari rata-rata tertimbang dari beta masing-masing saham individual. Dari menunjukkan bahwa return portofolio sebesar 0,01726 atau $1,73 \%$ per bulan. Untuk menentukan keputusan dalam berinvestasi tidak terlepas dari berbagai asumsi. Return portofolio yang dihitung diatas cukup menjanjikan karena portofolio tersebut diatas tingkat pengembalian pasar yaitu sebesar 0,00589 atau sebesar 0,59\%.

\section{Hasil Perhitungan Risiko Portofolio}

Untuk menentukan risiko dari portofolio, terlebih dahulu harus diketahui beta dari portofolio (systematic risk) yang dikuadratkan, variance market, serta unsystematic risk dari portofolio.

Dari perhitungan diatas menunjukkan bahwa variance portofolio sebesar 0.0085 atau sebesar $0.85 \%$. dapat dilihat bahwa tidak ada saham yang returnnya lebih besar daripada portofolio optimal, namun risiko yang ditanggung lebih kecil daripada portofolio. Oleh karena itu terbukti dengan membentuk portofolio optimal, dapat melakukan diversifikasi atau pengurangan risiko.

\section{SIMPULAN DAN SARAN}

\section{Simpulan}

1. Terdapat 10 saham yang memenuhi kriteria membentuk portofolio optimal yaitu: PT. Unilever Indonesia Tbk (UNVR), PT. Indofood CBP Sukses Makmur Tbk (ICBP), PT. Gudang Garam Tbk (GGRM), PT. Bank Central Asia Tbk (BBCA), PT. Charoen Pokphan Indonesian Tbk (CPIN), PT. Jasa 
Marga (Persero) Tbk (JSMR), PT. Lippo Karawaci Tbk (LPKR), PT. Bank Rakyat Indonesia (Persero) Tbk (BBRI), PT. Indocement Tunggal Prakasa Tbk (INTP) dan PT. Bank Mandiri (Persero) Tbk (BMRI).

2. Besarnya proporsi dana yang layak diinvestasikan pada ke 10 saham tersebut adalah UNVR sebesar 31,18\%; ICBP sebesar 20,40\%; GGRM seebesar 5,84\%; BBCA sebesar 14,83\%; CPIN 5,05\%; JSMR sebesar 10,08\%; LPKR 4,82\%; BBRI sebesar 6,01\%; INTP sebesar 1,16\%; dan BMRI sebesar 0,63\%.

\section{Saran}

1. Periode pengamatan tidak terlalu panjang hanya 60 bulan, yaitu dari Februari 2011- Januari 2016, oleh karena itu perlu perpanjangan periode agar hasil lebih memuaskan.

2. Penelitian ini hanya menggunakan saham yang termasuk LQ-45 yaitu hanya 45 saham yang memiliki likuiditas dan kapitalisasi pasar yang tinggi di pasar modal. Diharapkan untuk peneliti selanjutnya menggunakan seluruh saham yang terdaftar di Bursa Efek Indonesia.

\section{DAFTAR PUSTAKA}

Darmadji, T., dan Fakhrudin, H.M. 2001. Pasar Modal Indonesia. Edisi pertama. Jakarta: Salemba Empat.

Elton, Edwin J. and Martin J. Gruber. 1995. Modern Portfolio Theory and Investment Analysis. Fifth Edition. Toronto, Canada: John Wiley \& Sons, Inc.

Hartono, Jogiyanto. 2010. Teori Portofolio dan Analisis Investasi. Edisi kesepuluh. BPFE. Yogyakarta.

Husnan, Suad. 2001. Dasar-dasar Teori Portofolio dan Analisis Sekuritas. Edisi ketiga. Yogyakarta: UPP AMP YKPN.

Husnan, Suad. 2015. Dasar-dasar Teori Portofolio \& Analisis Sekuritas. Edisi kelima. Yogyakarta: UPP STIM YKPN.

Indonesian Stock Exchange. Fact Book. http://www.idx.co.id/idid/beranda/publikasi/factbook.aspx (diakses 7 November 2016)

Indonesian Stock Exchange. 2010. Buku Panduan Indeks Harga Saham Bursa Efek Indonesia.

Kasmir. 2010. Pengantar Manajemen Keuangan. Edisi Pertama. Jakarta: Kencana.

Tandelilin, Eduardus. 2001. Analisis Investasi dan Manajemen Portofolio. Edisi pertama. Yogyakarta: BPFE

Trihariyanto, Ranto. 2013. Analisis portofolio optimal berdasarkan model indeks tunggal. Skripsi. Universitas Yogyakarta.

www.Bi.go.id

www.Idx.co.id

www.Investing.com

www.Yahoofinance.com

"Analisis Pembentukan Portofolio Optimal dengan Menggunakan Single Index Model pada Emiten yang Termasuk Ke dalam Indeks LQ-45 Periode 2011- 2016”, 